\title{
Hemophagocytic lymphohistiocytosis associated with Epstein-Barr virus-positive diffuse large B-cell lymphoma, NOS of bone marrow-liver-spleen type: an autopsy case report
}

\author{
Hiroko Iizuka, ${ }^{1,2)}$ Yosuke Mori, ${ }^{1,3)}$ Noriaki Iwao, ${ }^{1)}$ Michiaki Koike, ${ }^{1)}$ Masaaki Noguchi ${ }^{2)}$
}

Lymphoma-associated hemophagocytic lymphohistiocytosis (HLH) has a significantly poor prognosis among secondary HLH. We describe the rare case of a 74-year-old female with secondary HLH presenting with a rapidly fatal course. Post-mortem examination revealed Epstein-Barr virus (EBV) -positive diffuse large B-cell lymphoma (DLBCL). We were unable to make a definite antemortem diagnosis because the patient did not exhibit lymphadenopathy and bone marrow biopsy demonstrated hemophagocytosis without evidence of lymphoma. She died of multiple organ failure on the twelfth day of hospitalization despite a temporary response to steroids. Autopsy revealed diffuse lymphoma cell infiltration of the bone marrow, liver and spleen, suggesting "bone marrow-liver-spleen" (BLS)-type large B-cell lymphoma (LBCL). BLS-type LBCL is a rare and clinically aggressive lymphoma, usually associated with fever, cytopenia and HLH. The disease has a high mortality rate due to the delay in diagnosis and a highly aggressive clinical course. Further studies are required to improve our understanding of this rare extranodal DLBCL.

Keywords: Epstein-Barr virus-positive diffuse large B-cell lymphoma, hemophagocytic lymphohistiocytosis, bone marrowliver-spleen-type large B-cell lymphoma, autopsy

\section{INTRODUCTION}

Hemophagocytic lymphohistiocytosis (HLH) is a rare immune disorder characterized by hypercytokinemia and tissue infiltration by cytotoxic lymphocytes and activated macrophages. ${ }^{1}$ Establishing a diagnosis of HLH can be difficult, and the patient often has a fatal course due to its heterogeneous etiology and nonspecific clinical and laboratory findings, which often mimic other conditions such as sepsis. ${ }^{2}$ HLH is classified as primary or secondary depending on the etiology. Secondary HLH is caused by a variety of underlying conditions such as infections, malignancies and autoimmune disorders. Lymphoma is the most common underlying cause of malignancy-associated HLH. ${ }^{3}$ We report an autopsy case of Epstein-Barr virus (EBV) -positive diffuse large B-cell lymphoma (DLBCL) not otherwise specified (NOS), in whom secondary HLH was suspected, but no definitive diagnosis was reached while the patient was alive. The patient had no lymphadenopathy on physical or imaging evaluation. Random skin biopsy to exclude intravascular large B-cell lymphoma (IVLBCL) yielded negative results. A subsequent extensive work-up also did not yield a definitive diagnosis. Post-mortem examination revealed diffuse infiltration of lymphoma cells in the bone marrow (BM), liver and spleen, and based on the distinctive clinical presentation, this aggressive B-cell neoplasm was identified as "bone marrow-liver-spleen"-type DLBCL (BLS-type LBCL). To the best of our knowledge, this is the first case report of EBV-positive BLS-type LBCL with HLH among 12 previous reports of BLS-type LBCL., 4 The purpose of this paper was to improve our understanding of this rare primary extranodal DLBCL by comparing the clinicopathological features with those previously reported.

\section{CASE REPORT}

The patient was a 74-year-old female with a medical history of type 2 diabetes mellitus and chronic renal failure.

\footnotetext{
Received: October 24, 2020. Revised: February 18, 2021. Accepted: March 8, 2021. J-STAGE Advance Published: May 14, 2021

DOI: $10.3960 /$ jslrt.20053

${ }^{1)}$ Department of Hematology, Juntendo University Shizuoka Hospital, Shizuoka, Japan, ${ }^{2}$ Department of Hematology, Juntendo University Urayasu Hospital, Chiba, Japan,

${ }^{3}$ Department of Hematology, Juntendo University School of Medicine, Tokyo, Japan

Corresponding author: Hiroko Iizuka, 2-1-1 Tomioka, Urayasu-shi, Chiba 279-0021, Japan. E-mail: hiiduka@juntendo.ac.jp

Copyright (C) 2021 The Japanese Society for Lymphoreticular Tissue Research

(c) BY-NC-SA This work is licensed under a Creative Commons Attribution-NonCommercial-ShareAlike 4.0 International License.
} 
She had no remarkable family history. She presented with fever and general weakness, which developed a few weeks prior to admission. She was admitted to another hospital where her laboratory tests revealed pancytopenia and liver dysfunction. After admission, her general condition gradually deteriorated and she developed disturbance of consciousness. Thus, she was transferred to our hospital for further evaluation and treatment. On admission, she had a temperature of $38.5^{\circ} \mathrm{C}$, blood pressure of $156 / 88 \mathrm{~mm} \mathrm{Hg}$ and she was semi-comatose. She did not exhibit lymphadenopathy.

Laboratory studies revealed pancytopenia (white blood cell count, $1,000 / \mu \mathrm{L}$ with $23.0 \%$ neutrophils, $38.0 \%$ lymphocytes and $35.0 \%$ monocytes; hemoglobin $7.7 \mathrm{~g} / \mathrm{dL}$; platelet count $2.9 \times 10^{\wedge} 4 / \mu \mathrm{L}$ ), liver dysfunction (aspartate aminotransferase, $441 \mathrm{U} / \mathrm{L}$; alanine aminotransferase, $138 \mathrm{U} / \mathrm{L}$; lactate dehydrogenase, 1,199 IU/L; total bilirubin, $2.1 \mathrm{mg} / \mathrm{dL}$ ) and renal dysfunction (blood urea nitrogen, $55.0 \mathrm{mg} / \mathrm{dL}$; creatinine, $2.14 \mathrm{mg} / \mathrm{dL}$ ). Her serum soluble interleukin-2 receptor and ferritin levels were high at $36,991 \mathrm{U} / \mathrm{mL}$ and $43,884 \mathrm{ng} /$ $\mathrm{mL}$, respectively. Anti-EBV antibody titers were 640 for EBVVCA-IgG, $<10$ for EBVVCA-IgM and 40 for EBVEBNA antibodies (Table 1). The EBV-DNA load in peripheral blood (PB) was not measured. Computed tomography (CT) demonstrated hepatosplenomegaly, mild pericardial effusion/pleural effusion and renal atrophy, but there was no evidence of systemic lymphadenopathy (Fig. 1a-c). Cerebral magnetic resonance imaging (MRI) revealed no abnormalities

Table 1. Laboratory findings on admission

\begin{tabular}{cccccc}
\hline WBC & 1,000 & $/ \mu \mathrm{L}$ & $\mathrm{TP}$ & 4.8 & $\mathrm{~g} / \mathrm{dL}$ \\
Neutrophil & 23 & $\%$ & $\mathrm{Alb}$ & 2.3 & $\mathrm{~g} / \mathrm{dL}$ \\
Lymphocytes & 38 & $\%$ & $\mathrm{~T}-\mathrm{Bil}$ & 2.1 & $\mathrm{mg} / \mathrm{dL}$ \\
Monocytes & 35 & $\%$ & $\mathrm{AST}$ & 441 & $\mathrm{IU} / \mathrm{L}$ \\
RBC & 237 & $\mathrm{x} 10^{4} / \mu \mathrm{L}$ & $\mathrm{ALT}$ & 138 & $\mathrm{IU} / \mathrm{L}$ \\
$\mathrm{Hb}$ & 7.7 & $\mathrm{~g} / \mathrm{dL}$ & $\mathrm{LDH}$ & 1,199 & $\mathrm{IU} / \mathrm{L}$ \\
Hct & 22.1 & $\%$ & $\mathrm{BUN}$ & 55.0 & $\mathrm{mg} / \mathrm{dL}$ \\
PLT & 2.9 & $\mathrm{x} 10^{4} / \mu \mathrm{L}$ & $\mathrm{Cre}$ & 2.14 & $\mathrm{mg} / \mathrm{dL}$ \\
PT-INR & 1.44 & & $\mathrm{UA}$ & 7.6 & $\mathrm{mg} / \mathrm{dL}$ \\
APTT/NC & $42.6 / 27.2$ & $\mathrm{sec}$ & $\mathrm{CRP}$ & 4.1 & $\mathrm{mg} / \mathrm{dL}$ \\
FIB & 80 & $\mathrm{mg} / \mathrm{dL}$ & $\mathrm{sIL}-2 \mathrm{R}$ & 36,991 & $\mathrm{U} / \mathrm{mL}$ \\
FDP & 24.1 & $\mu \mathrm{g} / \mathrm{dL}$ & $\mathrm{FER}$ & 43,884 & $\mathrm{ng} / \mathrm{ml}$ \\
HIV & - & & $\mathrm{IgG}$ & 907 & $\mathrm{mg} / \mathrm{dL}$ \\
HTLV-1 & - & & IgA & 163 & $\mathrm{mg} / \mathrm{dL}$ \\
EBVVCA IgM & $<10$ & & IgM & 37 & $\mathrm{mg} / \mathrm{dL}$ \\
EBVVCA IgG & 640 & & & & \\
EBV EBNA & 40 & & & & \\
\hline
\end{tabular}

WBC: white blood cell, RBC: red blood cell, $\mathrm{Hb}$ : hemoglobin, Hct: hematocrit, PLT: platelet, PT-INR: prothrombin time-international normalized ratio, APTT: activated partial thromboplastin time, NC: normal control, FIB: fibrinogen, FDP: fibrin degradation products, EBVVCA: Epstein-Barr virus, viral capsid antigen, EBNA: Epstein-Barr virus nuclear antigen, TP: total protein, Alb: albumin, T-Bil: total bilirubin, AST: aspartate transaminase, ALT: alanine transaminase, LDH: lactate dehydrogenase, BUN: blood urea nitrogen, Cre: creatinine, UA: uric acid, CRP: C-reactive protein, sIL-2R: soluble interleukin-2 receptor, FER: ferritin, IgG: immunoglobulin G, IgA: immunoglobulin A, IgM: immunoglobulin $\mathrm{M}$. to explain the disturbed consciousness (Fig. 1d). Considering a diagnosis of intravascular large B-cell lymphoma (IVLBCL), random skin biopsy was performed, although her normalappearing skin exhibited no pathological changes. BM examination demonstrated hypocellularity, hemophagocytosis (Fig. 2a) and the presence of large abnormal lymphoid cells (Fig. 2b). However, there was no evidence of an abnormal cell population on flow cytometry (FCM) of the BM. The cause was considered to be insufficient material for BM aspiration due to her poor general condition. Cerebrospinal fluid examination revealed no abnormality. Therefore, she was diagnosed with secondary HLH of unknown etiology and initially treated using prednisolone at $50 \mathrm{mg} /$ day $(1 \mathrm{mg} /$ $\mathrm{kg}$ /day). However, her pancytopenia, liver dysfunction and renal dysfunction deteriorated daily. She died of multiple organ failure on the twelfth day of hospitalization. Postmortem examination was subsequently performed with her family's consent.

\section{AUTOPSY FINDINGS}

On autopsy, the patient had hepatomegaly (weight $=$ 1,300 grams), splenomegaly (weight $=220$ grams) and ascites $($ volume $=1,500 \mathrm{ml})$. A detailed autopsy survey revealed slight swelling of the para-aortic lymph node (LN), which was not observed on antemortem imaging. The large abnormal lymphoid cells diffusely infiltrated the liver and spleen. Immunohistochemistry revealed CD20(+) and CD3(-) cells, and nuclear staining demonstrated the presence of $\mathrm{Ki}-67$ in approximately $70-80 \%$ of cells (Fig. 2c-j). Unlike the antemortem BM sample, postmortem BM was hypercellular with infiltration of large abnormal lymphoid cells with multiple nucleoli (Fig. 2k, 1). Immunohistochemistry for a definite diagnosis was performed on the para-aortic LN, which was not the major lesion. The tumor cells of para-aortic LN were CD20(+), CD3(-), CD5(-), CD10(-), BCL2(+), BCL6(-) and MUM1(+). The nuclei of approximately $80 \%$ of the cells were positive for Ki-67. EBER in situ hybridization (ISH) demonstrated positive signals in the tumor cells for the expression of LMP1 and EBNA2 (focally), suggesting latency III (Fig. 3a-h). A monoclonal EBV terminal repeat band pattern was observed in the DNA extracted from the para-aortic LN specimen by Southern blotting. No evidence of MYC rearrangement was found on fluorescence in situ hybridization (FISH) analysis. FCM of the ascitic fluid demonstrated an abnormal B-cell population with the expression of CD20+/CD19+/CD10-/CD30+/kappa surface light chains (Fig. 4). A monoclonal rearrangement of IGH genes, but not TCR genes, was found in the liver, spleen and paraaortic LN. We performed a detailed survey, and reconfirmed the lack of intrasinusoidal and intravascular lymphoma cells in the liver, spleen and BM. These morphological and immunophenotypic results supported a diagnosis of EBVpositive DLBCL, NOS. 
$\mathbf{a}$

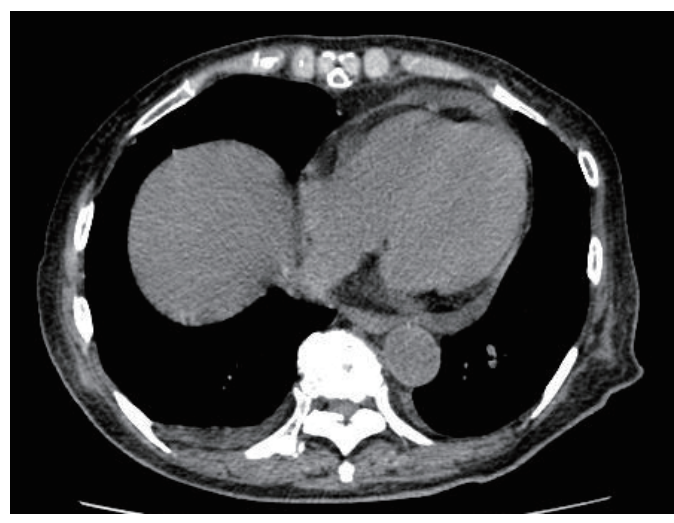

c

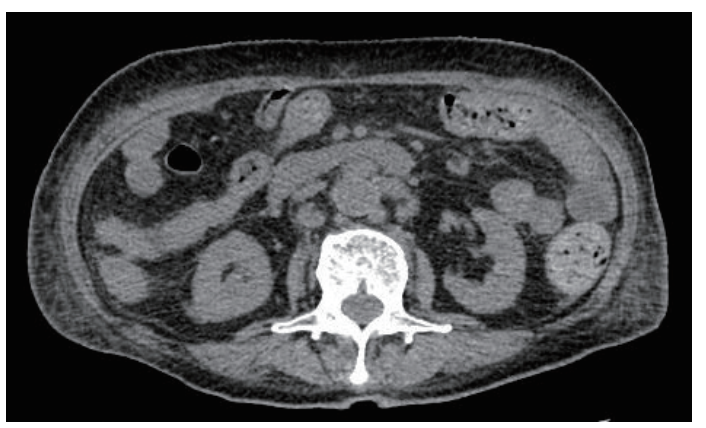

b

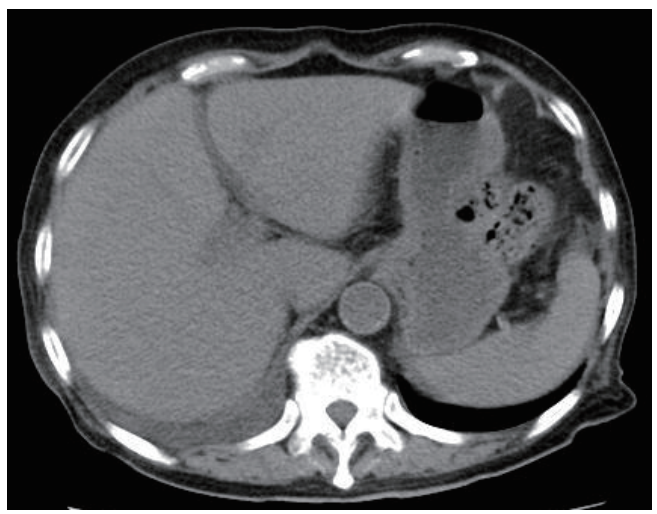

d

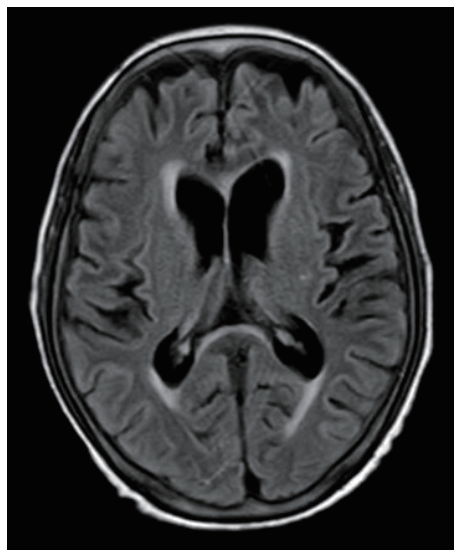

Fig. 1. Radiological images. Computed tomography image showing pericardial and pleural effusion (a), hepatosplenomegaly $(\boldsymbol{b})$ and renal atrophy $(\boldsymbol{c})$. Cerebral magnetic resonance imaging showed no abnormalities $(\boldsymbol{d})$.

\section{CYTOGENETIC FINDINGS}

Cytogenetic analyses of BM samples obtained during her lifetime were established after death. Analysis revealed the following complex karyotype: $67<2 \mathrm{n}>$, XX, + add(1) $(\mathrm{p} 13),+2,+\operatorname{add}(3)(\mathrm{q} 21),-4, \operatorname{add}(4)(\mathrm{q} 21), \operatorname{add}(5)(\mathrm{q} 31),-6, \operatorname{add}(7)$ (q11.2), -9,-9,-11,+12, add(12)(q13)x2,-13,-14,-15,$16,+\operatorname{add}(17)(\mathrm{q} 25) \times 2,+\operatorname{add}(18)(\mathrm{q} 21),+19,-20,-20,-$ $22,+\mathrm{r},+24 \operatorname{mar}[1] / 46, \mathrm{XX}[19]$.

\section{DISCUSSION}

In a nationwide survey of HLH patients in Japan, lymphoma-associated HLH (LAHS) accounted for approximately one-fifth of the secondary HLH patients. ${ }^{6}$ LAHS was observed exclusively in adults, especially in the elderly $(\geq 60$ years of age), as in our case. The predominant histology of B-cell lymphoma-associated LAHS (B-LAHS) was DLBCL, especially IVLBCL. ${ }^{7}$ In the present case, we considered the possibility of IVLBCL based on the elderly onset of HLH without lymphadenopathy. However, IVLBCL was excluded because of the absence of infiltration of lymphoma cells in blood vessels by histological examination. B-LAHS due to EBV-positive DLBCL, NOS, as in this case, is considered rare. Although there are several large population-based observational studies on LAHS, the prevalence of EBER positivity is unknown because only few reports exist to date. ${ }^{8,9}$ These studies reported a low incidence of EBV-positive DLBCL, NOS as the underlying disease of LAHS, with an incidence rate of approximately $1.4-3.4 \%$.

EBV-positive DLBCL, NOS is a clinicopathological entity recognized in the revised 4th edition of the 2016 classification of the World Health Organization (WHO). ${ }^{10}$ Previous reports emphasized that EBV-positive DLBCL, NOS typically involves extranodal sites, ${ }^{11}$ with the lung and gastrointestinal tract being the most common. On autopsy in this case, extranodal lesions were found in the BM, liver and spleen. Involvement of these three extranodal sites is a rare event in EBV-positive DLBCL compared with EBV-negative DLBCL (1.25\% vs. 13.1\%). ${ }^{12}$ Furthermore, although lymphoma cell infiltration of the para-aortic LN was observed, the resulting LN enlargement was insufficient to be discernible on antemortem imaging. We believe that the main sites of lesions were the BM, liver and spleen. This led to a diagnosis of "BLS-type LBCL". Previously reported cases of BLS-type LBCL had many areas of slight LN swelling (usually 
a

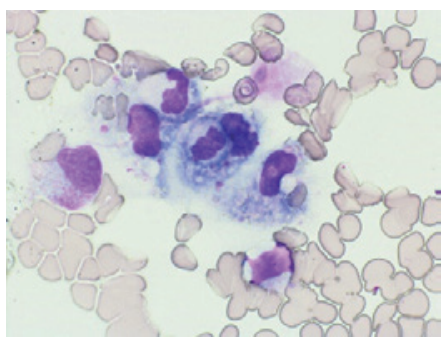

d

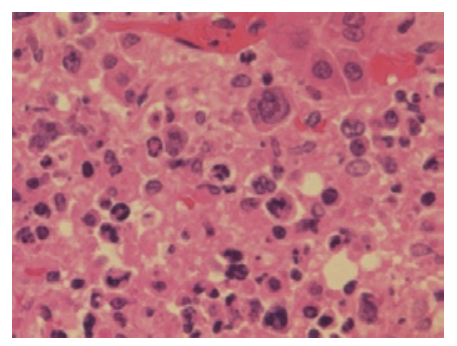

g

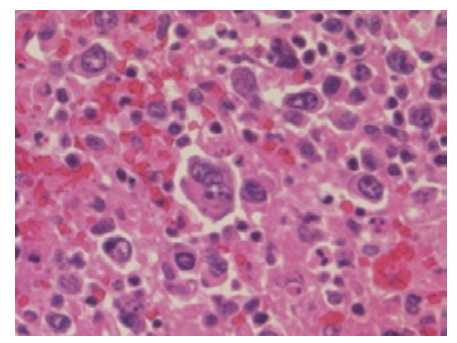

h

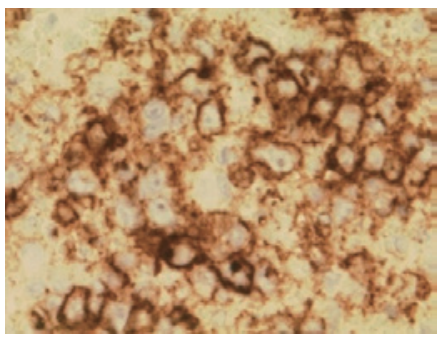

b

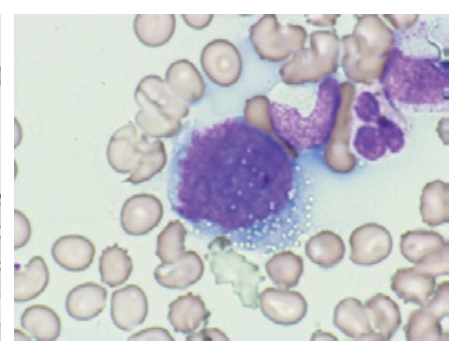

e

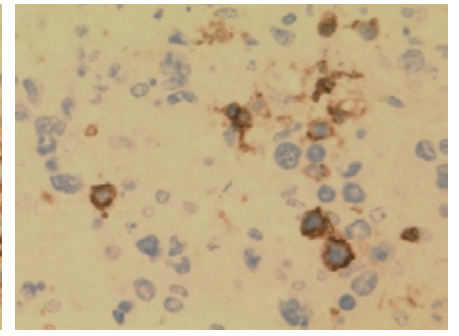

i

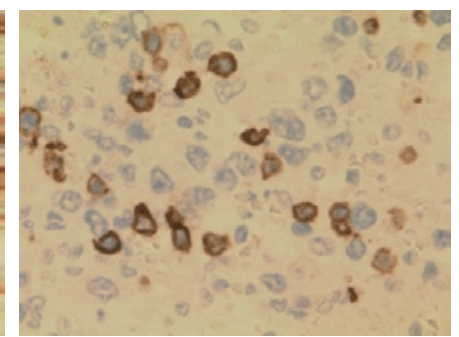

f

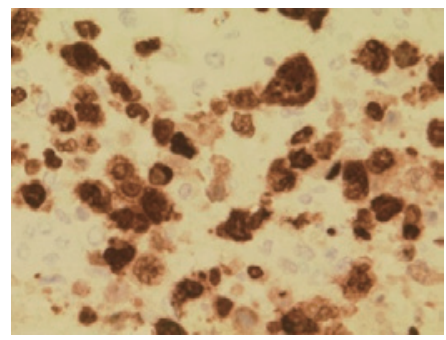

j

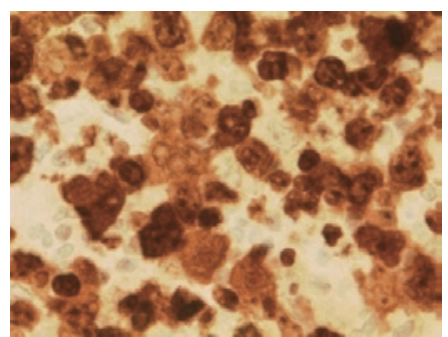

k

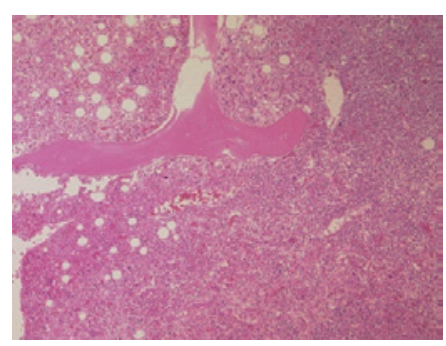

l

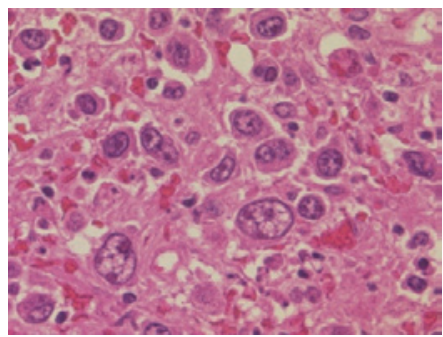

Fig. 2. Large B-cell lymphoma of the liver, spleen and bone marrow

Antemortem bone marrow examination showed hemophagocytosis ( $\boldsymbol{a}$, May-Giemsa staining, original magnification x400) and the presence of large abnormal lymphoid cells ( $\boldsymbol{b}$, May-Giemsa staining, original magnification x1,000). There was diffuse proliferation of large lymphocytes in the liver and spleen $(\boldsymbol{c}, \boldsymbol{g}$, hematoxylin-eosin staining, original magnification x400). The large lymphocytes were CD20-positive $(\boldsymbol{d}, \boldsymbol{h})$ and CD3-negative $(\boldsymbol{e}, \boldsymbol{i})$. The MIB1 index of large lymphocytes was $70-80 \%(\boldsymbol{f}, \boldsymbol{j})$. The middle part in the figure $(\boldsymbol{c}-\boldsymbol{f})$ shows the findings in the liver and the lower part $(\boldsymbol{g}-\boldsymbol{j})$ shows those in the spleen. Large lymphocytes were also interspersed in the bone marrow $(\boldsymbol{k}$, hematoxylin-eosin staining, original magnification $\mathrm{x} 40, \quad l$, hematoxylin-eosin staining, original magnification $\mathrm{x} 400$ ).

less than $3 \mathrm{~cm}$ ) and exhibited clinical features consistent with those in this case, namely the high incidence of secondary HLH and rapidly fatal course. To date, there is only one series of 11 cases and one case report of BLS-type LBCL, and the clinical behavior was highly aggressive in all cases (Table 2). HLH was observed at a high incidence of eight of 12 patients $(66 \%)$. Eleven of the 12 patients $(92 \%)$ died, and early death within 1 month of admission occurred in five $(42 \%)$, reflecting the markedly poor prognosis. Immunohistochemical analysis revealed a high Ki-67 index ( $\geq 80 \%$ in all patients tested). Per the Hans algorithm based on the expression of CD10, BCL6 and MUM1, ${ }^{13} 11$ of the 12 cases were classified into the nongerminal center B-cell-like (non-GCB) subgroup. Prior studies suggest that BM 
a

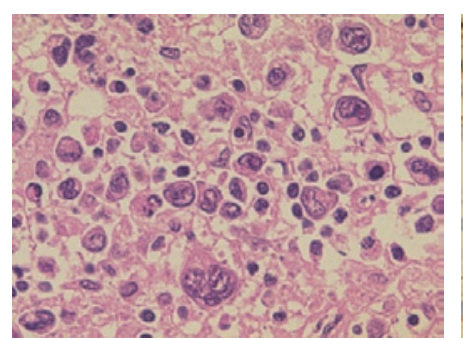

e

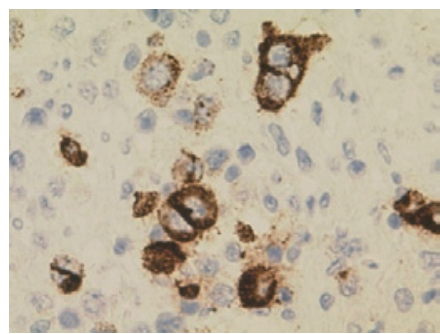

b

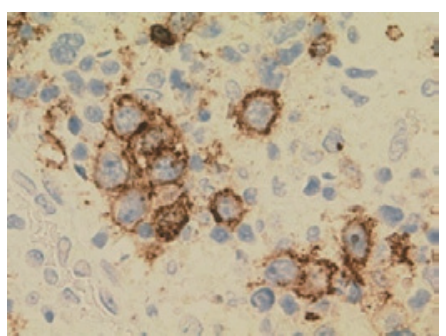

f

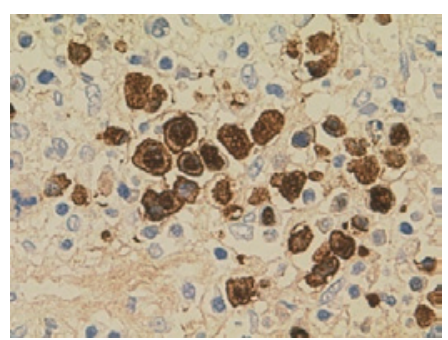

c

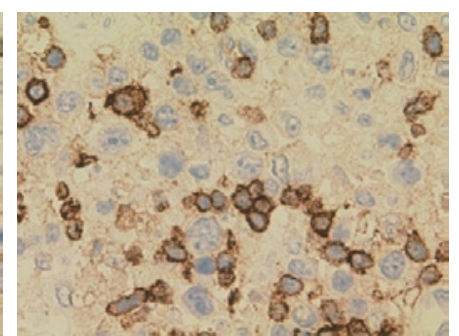

g

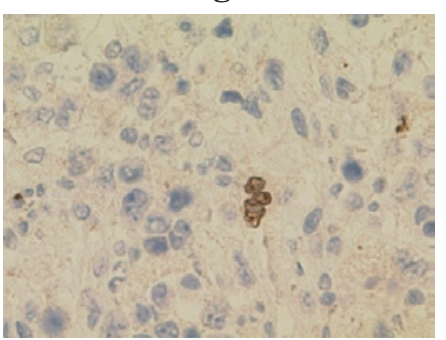

d

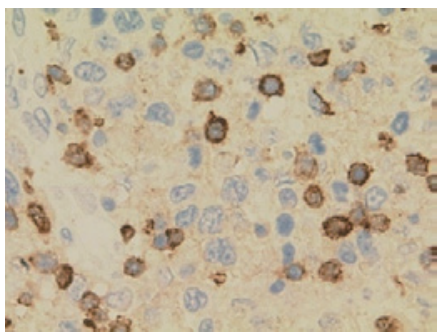

$\mathbf{h}$

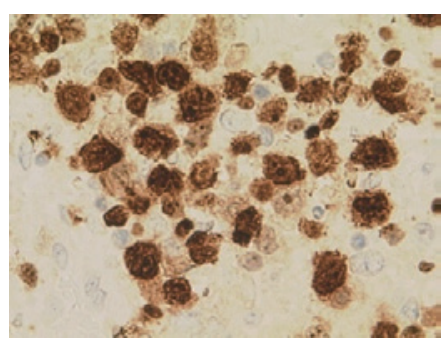

Fig. 3. EBV-positive diffuse large B-cell lymphoma of the para-aortic lymph node evaluated post-mortem

Large lymphocytes were interspersed with small lymphocytes (a, hematoxylin-eosin staining, original magnification x400). Large lympho-

cytes were CD20-positive $(\boldsymbol{b})$, CD3-negative $(\boldsymbol{c})$, CD5-negative $(\boldsymbol{d})$, LMP-1-positive $(\boldsymbol{e})$, EBER-positive $(\boldsymbol{f})$ and focally EBNA2-positive $(\boldsymbol{g})$. The MIB1 index of large lymphocytes was $80 \%(h)$.
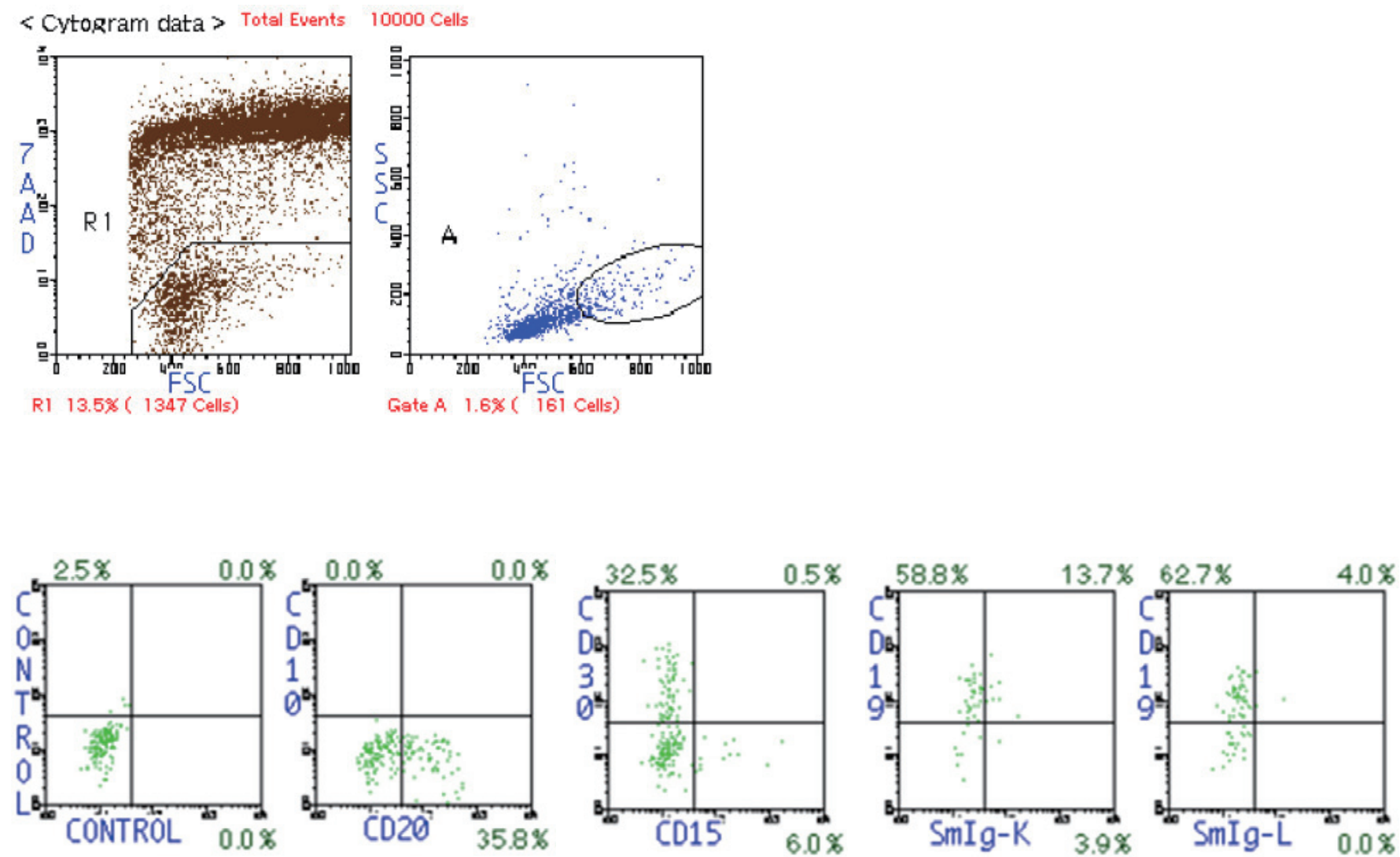

Fig. 4. Flow cytometry of the ascitic fluid revealed that the large cells were positive for CD19, CD20, CD30 and kappa 
Table 2. Clinical features and immunohistochemical findings of reported patients who presented with large B-cell lymphoma initially manifesting in the bone marrow, liver and spleen (BLS-type) without lymphadenopathy

\begin{tabular}{|c|c|c|c|c|c|c|c|c|c|c|c|c|c|c|}
\hline Case & Age/sex & Fever & $\mathrm{H} / \mathrm{S}$ & $\begin{array}{c}\mathrm{LDH} \\
(\mathrm{IU} / \mathrm{L})\end{array}$ & HLH & CD5 & CD10 & BCL2 & BCL6 & MUM1 & Ki67 & EBER & Treatment & $\begin{array}{l}\text { Outcome } \\
\text { (days) }\end{array}$ \\
\hline Our case & $74 / \mathrm{F}$ & + & $+/+$ & 1,199 & + & - & - & + & - & + & $80 \%$ & + & - & Dead (12) \\
\hline 1 & $26 / \mathrm{F}$ & + & $-1+$ & 293 & - & ND & - & - & + & + & ND & - & $\begin{array}{c}\text { CHOPx3, } \\
\text { R-ESHAP, } \\
\text { PBSCT }\end{array}$ & Alive $(1,560)$ \\
\hline 2 & $73 / F$ & + & $-1+$ & 293 & + & ND & - & - & - & + & ND & - & $\begin{array}{l}\text { CHOPx1, } \\
\text { R-CHOPx5 }\end{array}$ & Dead (784) \\
\hline 3 & $44 / \mathrm{M}$ & + & $-1+$ & 745 & - & - & - & + & - & - & $95 \%$ & - & $\begin{array}{l}\text { CEOPx1, } \\
\text { R-CEOPx5, } \\
\text { R-ESHAPx4, } \\
\text { PBSCT }\end{array}$ & Dead (551) \\
\hline 4 & $54 / \mathrm{M}$ & + & $-1+$ & 727 & + & - & - & + & + & + & $80 \%$ & - & СHOPx6 & Dead (285) \\
\hline 5 & $80 / \mathrm{M}$ & + & $+/+$ & 319 & + & ND & - & + & + & + & $90 \%$ & - & - & Dead (17) \\
\hline 6 & $72 / \mathrm{M}$ & + & $-1+$ & 1,255 & - & - & - & + & - & + & $90 \%$ & + & - & Dead (8) \\
\hline 7 & $76 / \mathrm{M}$ & + & $-1+$ & 426 & + & - & - & - & + & - & $90 \%$ & - & - & Dead (6) \\
\hline 8 & $61 / \mathrm{M}$ & + & $-1+$ & 160 & + & ND & - & + & - & + & $90 \%$ & - & - & Dead (4) \\
\hline 9 & $75 / \mathrm{M}$ & + & $-1+$ & 4,464 & + & + & - & + & - & + & $95 \%$ & - & - & Dead (4) \\
\hline 10 & $69 / \mathrm{M}$ & + & $-1+$ & 482 & - & - & - & + & + & + & $95 \%$ & - & R-CVADx6 & Dead (84) \\
\hline 11 & $60 / \mathrm{M}$ & + & $+/+$ & 2,266 & + & - & - & + & + & + & $95 \%$ & - & R-CVADx6 & Dead (224) \\
\hline 12 & $73 / \mathrm{F}$ & + & $+/+$ & 1,010 & + & NA & - & + & NA & + & NA & - & R-CHOP & Dead (51) \\
\hline
\end{tabular}

HS: hepatomegaly/splenomegaly, HLH: hemophagocytic lymphohistiocytosis, CHOP: cyclophosphamide, doxorubicin, vincristine and prednisolone (E, epirubicin), R-ESHAP: rituximab, etoposide, methylprednisolone, cytarabine and cisplatin, CVAD: cyclophosphamide, vincristine, doxorubicin hydrochloride (adriamycin) and dexamethasone, PBSCT: peripheral blood stem cell transplantation, F: female, M: male, ND: not done, NA: not available, EBER: Epstein-Barr virus-encoded RNA detected by in situ hybridization.

involvement with DLBCL portends a refractory status and poor prognosis. ${ }^{14}$ Furthermore, BLS-type LBCL is associated with a higher incidence of HLH and almost always has a fatal course. In addition, it is different from the more common BM involvement with DLBCL, suggesting that further studies are needed to determine whether BLS-type LBCL should be recognized as a separate subtype. Moreover, in this case, EBV positivity was considered a risk factor related to the biological features of the tumors. In the previous report, there was only one case of BLS-type LBCL with EBER positivity, and this is the only case of EBV-latency III, as indicated by EBNA2 positivity. Latency type III, with positivity for EBNA2, is observed in approximately $30 \%$ of EBV-positive DLBCL cases and is associated with a markedly immunodeficient state. Patients with EBV-positive DLBCL with latency type III have a significantly shorter OS than patients with latency type I/II (no EBNA2 expression). ${ }^{15}$ EBV-mediated oncogenesis and host immunodeficiency were considered to be complexly related, leading to the markedly poor prognosis in this case. We believe that our case highlights the specificity and diversity of BLS-type LBCL.

In conclusion, we described a markedly rare case of EBV-positive BLS-type LBCL presenting with associated HLH. The clinical presentation and disease course of BLStype LBCL are particularly severe, with high mortality rates during the first weeks to months. However, this lymphoma is a rare and controversial entity because it may be a specific type of extranodal DLBCL. Therefore, increased disease recognition and development of effective therapeutic strate- gies are needed for this rare but clinically aggressive lymphoma "BLS-type LBCL".

\section{CONFLICT OF INTEREST}

The authors have no significant relationships with or financial interests in any commercial companies pertaining to this article.

\section{REFERENCES}

1 George MR. Hemophagocytic lymphohistiocytosis: review of etiologies and management. J Blood Med. 2014; 5 : 69-86.

2 Okabe T, Shah G, Mendoza V, et al. What intensivists need to know about hemophagocytic syndrome: an underrecognized cause of death in adult intensive care units. J Intensive Care Med. 2012; 27 : 58-64.

3 Chandrakasan S, Filipovich AH. Hemophagocytic lymphohistiocytosis: advances in pathophysiology, diagnosis, and treatment. J Pediatr. 2013; 163 : 1253-1259.

4 Yeh YM, Chang KC, Chen YP, et al . Large B cell lymphoma presenting initially in bone marrow, liver and spleen: an aggressive entity associated frequently with haemophagocytic syndrome. Histopathology. 2010; 57 : 785-795.

5 Lyapichev KA, Chapman JR, Iakymenko O, et al . Bone marrow-liver-spleen type of Large B-cell lymphoma associated with hemophagocytic syndrome: A rare aggressive extranodal lymphoma. Case Rep Hematol. 2017; 2017 : 8496978.

6 Ishii E, Ohga S, Imashuku S, et al . Nationwide survey of 
hemophagocytic lymphohistiocytosis in Japan. Int J Hematol. 2007; $86: 58-65$.

7 Takahashi N, Chubachi A, Miura I, Nakamura S, Miura AB. [Lymphoma-associated hemophagocytic syndrome in Japan]. Rinsho Ketsueki. 1999; 40 : 542-549 [in Japanese].

8 Bigenwald C, Fardet L, Coppo P, et al . A comprehensive analysis of Lymphoma-associated haemophagocytic syndrome in a large French multicentre cohort detects some clues to improve prognosis. Br J Haematol. 2018; 183 : 68-75.

9 Han AR, Lee HR, Park BB, et al . Lymphoma-associated hemophagocytic syndrome: clinical features and treatment outcome. Ann Hematol. 2007; 86 : 493-498.

10 Swerdlow SH, Campo E, Pileri SA, et al . The 2016 revision of the World Health Organization classification of lymphoid neoplasms. Blood. 2016; 127 : 2375-2390.

11 Ok CY, Papathomas TG, Medeiros LJ, Young KH. EBVpositive diffuse large B-cell lymphoma of the elderly. Blood. $2013 ; 122: 328-340$.
12 Witte HM, Merz H, Biersack H, et al . Impact of treatment variability and clinicopathological characteristics on survival in patients with Epstein-Barr-Virus positive diffuse large B cell lymphoma. Br J Haematol. 2020; 189 : 257-268.

13 Hans CP, Weisenburger DD, Greiner TC, et al . Confirmation of the molecular classification of diffuse large B-cell lymphoma by immunohistochemistry using a tissue microarray. Blood. 2004; $103: 275-282$.

14 Sehn LH, Scott DW, Chhanabhai M, et al . Impact of concordant and discordant bone marrow involvement on outcome in diffuse large B-cell lymphoma treated with R-CHOP. J Clin Oncol. 2011; 29 : 1452-1457.

15 Stuhlmann-Laeisz C, Borchert A, Quintanilla-Martinez L, et al . In Europe expression of EBNA2 is associated with poor survival in EBV-positive diffuse large B-cell lymphoma of the elderly. Leuk Lymphoma. 2016; 57 : 39-44. 